\title{
Project-based optical design practice course and teamwork: from a programmer to a lens designer
}

Xiaotong Li, Weige Lv, Zhaofeng Cen, Lingying Jiang, Dong Liu, et al.

Xiaotong Li, Weige Lv, Zhaofeng Cen, Lingying Jiang, Dong Liu, Jianfeng Xu, "Project-based optical design practice course and teamwork: from a programmer to a lens designer," Proc. SPIE 11143, Fifteenth Conference on Education and Training in Optics and Photonics: ETOP 2019, 111432A (2 July 2019); doi: 10.1117/12.2523779

SPIE Event: Fifteenth Conference on Education and Training in Optics and Photonics: ETOP 2019, 2019, Quebec City, Quebec, Canada 


\title{
Project-based optical design practice course and teamwork: from a programmer to a lens designer
}

\author{
Xiaotong Li, Weige Lv ${ }^{*}$, Zhaofeng Cen ${ }^{* *}$, Lingying Jiang, Dong Liu, Jianfeng Xu \\ State key laboratory of modern optical instrumentation, College of optical science and engineering, \\ Zhejiang University, Hangzhou 310027, P. R. China
}

\begin{abstract}
Computer Aided Optical System Design is an engineering practice course for undergraduate students in College of Optical Science and Engineering, Zhejiang University. When the students have just completed Applied Optics course in spring-summer semester, they will take the practice course in a short semester in summer vocation. This is a projectbased practice course, including optical software developing and lens design. The teaching idea is not only to improve the students' engineering skills but also to connect different knowledge they have studied, to build a comprehensive knowledge structure, and to develop the team spirit, organizational capability, leadership and communication skills. This course is designed as an engineering project with a contract between the teacher group and every design group of 3 students. In this paper we describe the course program and how to provide a chance to combine different knowledge into a project. In every student group, developing ray trace software of good reliability is the teamwork, and each student will design a photographic lens independently. The lens with the best optical performance will be selected as the team's result, and be drawn into a system diagram and part drawings. The whole process is both competitive and cooperative, and gives the students the experiences of programmers and lens designers. Most of the students appreciated the practice course and named it as "the most memorable short semester".
\end{abstract}

Keywords: Optics education, practice course, optical system design, project-based course, teamwork

\section{INTRODUCTION}

In College of Optical Science and Engineering, Zhejiang University, the curriculum includes the following modules: general education courses, professional education courses, personality courses, practice courses and other courses. Applied Optics, Applied Optics Lab and Computer Aided Optical System Design ${ }^{[1]}$ belong to the series of courses in the fields of geometrical optics and optical system design. The undergraduate students who have studied the knowledge of geometrical optics, principles of classical optical systems and aberrations in spring-summer semester will have an engineering practice training in two weeks in summer vocation. How to design the practice training to let the students combine what they have learned, to build engineering idea, and to understand the procedure of optical design, there were what we thought in many years.

In order to grow students' abilities for solving optical design problems independently by using their knowledge of related fields, the students will learn to develop simple software with the functions of ray tracing and aberration calculating as programmers, to understand the principles of optimization design on optical systems, and will use optical software to design a photographic lens as designers. It is very important for the students to become optical designer.

Before 2015, we offered Computer Aided Optical System Design course in the autumn-winter semester. This practice course lasted for 8 weeks in that time. Although every week we had only one afternoon or 4 hours, but the students have much time to continue their work after class. Since 2016, the time of this practice course has been moved to the short term in summer, and lasts only 10 workdays. In 2017, ITMO University reported educational programs in optical design and engineering oriented for different background level, "such are: introduction into optical engineering, introduction into applied and computer optics, Optical system design, Image modeling and processing, Design of optical devices and components." "[2] This program lasts 4 weeks. Undoubtedly, the period of 10 workday gives us a great challenge. In this paper the teaching design, difficulties and strategies are presented.

* Ivweige@zju.edu.cn; phone (86)571-87951681; fax (86)571-87951617; opt.zju.edu.cn

**cenzf@zju.edu.cn; phone (86)571-87952302; fax (86)571-87952302; opt.zju.edu.cn

Fifteenth Conference on Education and Training in Optics and Photonics: ETOP 2019, edited by

Anne-Sophie Poulin-Girard, Joseph A. Shaw, Proc. of SPIE Vol. 11143, 111432A · C 2019

SPIE, ICO, IEEE, OSA · CCC code: 0277-786X/19/\$18 · doi: 10.1117/12.2523779 


\section{PROJECT-BASED TEACHING DESIGN}

\subsection{Academic background of the students}

Due to the curriculum in the high schools of China, optics is an elective course in physics. In university entrance examination, only several percent of the score is involved in optics, although in our opinion the students should have learned more optics. Because of this, in our College, Applied Optics is one of the most important courses. The content includes philosophy of geometrical optics, principles of perfect optical systems, classical optical systems and the theories of aberrations. However, as undergraduate students who will be optical engineers, it is also a fundamental skill to use optical software to design optical systems.

This engineering training is an optical design practice course for these students. They are in grade 2, and have studied C Programming, Geometrical Optics and Drawing. But these courses they have learned are independent from each other, and they do not have an opportunity to combine the knowledge of all these courses until they have the practice training. For example, they have completed the course of C Program before one year, but no one has developed a useful program to calculate some parameters of optical systems. They have known how to draw an element drawing, but no one has drawn an optical system or an optical element. So we believe a design practice is necessary for combining all they have learned, and this practice is a very good chance to connect what they have learned and optical manufacture, and is also a chance to know how to calculate the imaging qualities of optical systems. In our opinion, this practice course is such a course, and is important for building a comprehensive knowledge structure, developing the team spirit, organizational capability, and leadership and communication skills.

\subsection{Practice teaching design}

As an engineering training practice, we hope that it to be like a real optical design project. So we take a contract as a beginning so as to simulate an engineering project. This project includes 4 parts as following:

\section{(1) Software development}

There is optical design practice in many universities including designing optical systems using optical software, but usually software development is not be included ${ }^{[3]}$. Programming ability is a general skill for a modern engineer. As describing above, the students do not have an opportunity to complete a programming project. Ray tracing is available for this training. When we start an optical design, the first thing is to design Gaussian structure according to the principles of perfect optical systems. Then we design every optical group into real lenses. The next step is to optimize the system by ray tracing. So ray tracing is the fundamental calculation in optical design software. All of the merit functions are calculated by ray tracing. Certainly, we have only two weeks to complete this training, so the typically ray trace and the calculation for some geometrical aberrations are selected for the training.

Calculating aberrations and ray tracing are available for training the programming abilities. As known that an optical imaging system consists of a number of optical surfaces, thicknesses and optical materials, and gives image of an object at a certain distance with the light of a certain range of wavelength. For saving these parameters in computer a reasonable and maintainable data structure needs to be designed at the start of programming. When calculating aberrations, the rays come from different field and different point at the entrance surface with different wavelength will be traced in this program. So it is necessary to programming a nested loop structure, in which there are at least a loop of wavelength, a loop of field and a loop of aperture. This is a typical multiple circulation. It is why we take software development as a part of the practice.

(2) A photographic lens design

There are many types of optical systems. Only in classical optical systems, there are microscope objective lens, eyepiece, telescope, photographic lens, projection lens, and so on. And laser system, Fourier transformation system and some others are known as special or modern optical systems because of some of their special merit criteria.

As an optical system design training project, we believe that photographic lens design is applicable for the practice course. Photographic lens is a system with all kinds of aberrations, and involves the principles of optical group combination. The design on this system is individual. This means that with the same initial optical parameters as the beginning, every student will design one's own optical system with different parameters individually. Our statement of work (SOW) only gives the focal length, F number, the image size and pixel size, and the smallest MTF value at the Nyquist space frequency. The students have enough space to design independently. At the end, of course, every student 
will design a lens that meets all of the technical criteria, and the lens with the best optical performance in each student group will be selected as the design result of the group.

\section{(3) Drawing}

Having selected the best design of each group, the three students in one group will draw the optical system and every optical element, and indicate tolerances according to the requirements of optical workshop testing method. This is a very good opportunity for the students who do not have the workshop experiences, and make them know the lens shape and other parameters are limited by optical manufacturing, and know how to produce optical elements and assembly a lens.

\section{(4) Report presentation and defense}

Each student group should write a report in which the following items are necessary: main flowchart, detail flowcharts and a manual of their software, typical aberration data calculated by their software, and a comparing table in which the data calculated by their own software and the data calculated by ZEMAX are filled in, layouts of the lenses designed by every member, aberration data and curves, spot diagram and MTF of the group's design with the best performance. At the end of the report, they write a review of their design, including their experiences and feelings in the two weeks.

In the last day of the short term, every student group submits their report and has a presentation and defense.

Form the above we can see that the practice is not an easy project. In our class, every group of three students complete the project independently, and in one group they complete the project by sharing tasks and working together. For example, the program can be divided into several sub-programs, such as data input, pre-calculation, result output, paraxial ray tracing, tangential ray tracing, finding the positions of cardinal points, and aberration calculation. The subprogram of aberration calculation is also divided into several down-level subroutines, such as spherical aberration, coma, the third order astigmatism and field curvature, distortion, and longitudinal and lateral chromatic aberrations. The aberration calculation sub-program will input data from the main program, and call the specified aberration calculation sub-program to get the aberration value, and then return. Every sub-program of aberration calls the paraxial ray tracing sub-program and tangential ray tracing sub-program. Due to the limited period, only 2 or 3 days could be used to develop the program. This puts a lot of pressure on the students, and make them share the tasks and cooperate carefully.

\section{DIFFICULTIES AND STRATEGIES}

For the students, this practice course means a new learning model, and some difficulties have been appeared in the implementation process, mainly in the following:

1. The period is only 2 weeks, and the task is challenging and not experienced for the students

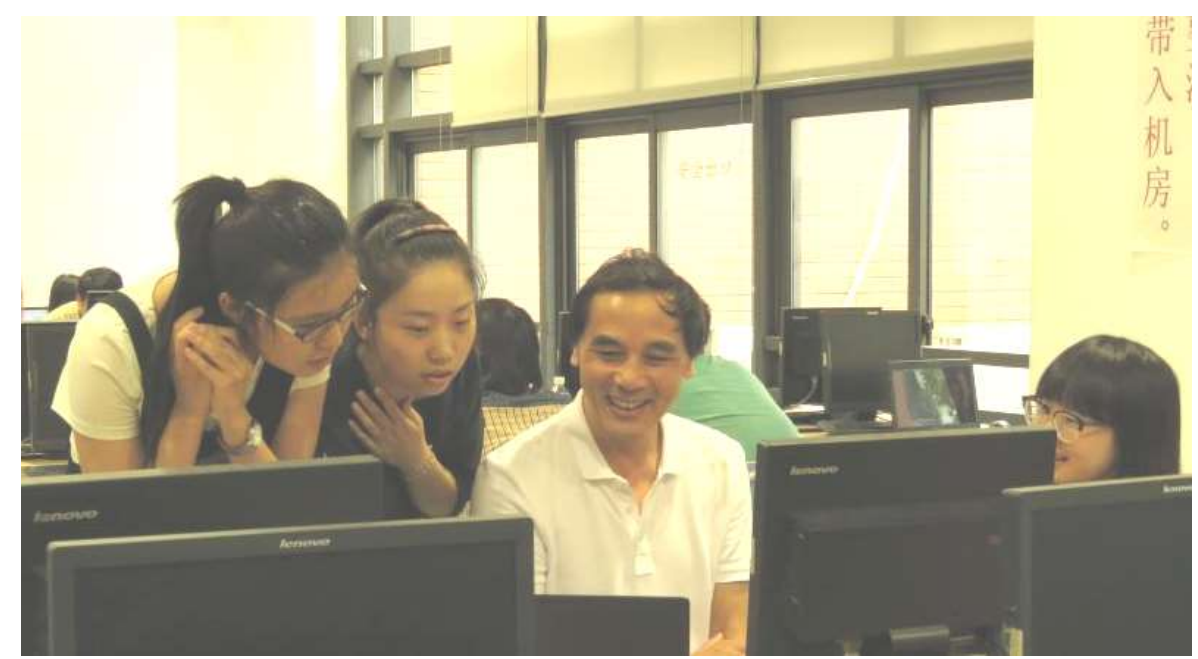

Figure 1. Professor Zhaofeng Cen is instructing students to design their optical systems. 


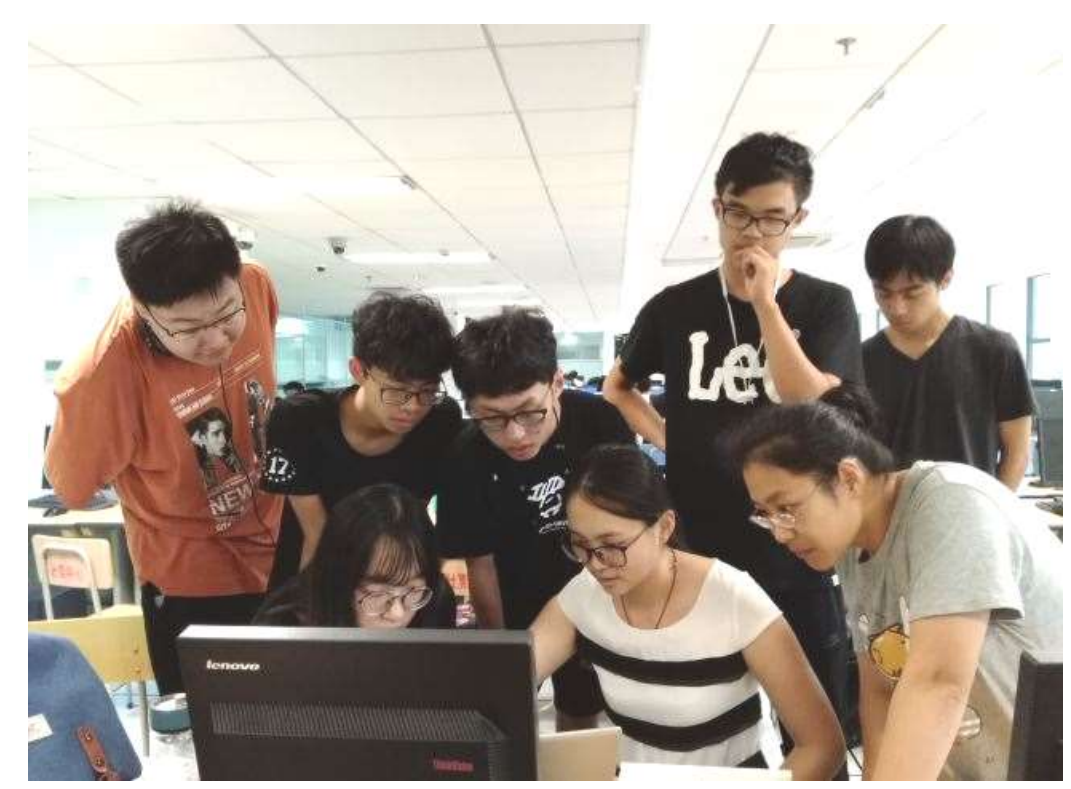

Figure 2. A instructor and two teaching assistant are demonstrate the method of drawing (from left to right in front row: teaching assistant Minli Chen, teaching assistant Anqi Jiang, instructor and engineer Lingying Jiang; back row: 5 students).

At the beginning, over $40 \%$ of the students feel difficult. In order to help them to complete the task, we establish the minimum standards. We give outstanding students the space to show their abilities, and enable most students to complete the practice. The program design requires cooperation of every student in one group, and each student must at least design a lens that meets the technical requirements. Our goal is mainly to let the students experience the whole process of optical design by cooperation. Every year, the difficulty of the task is controlled by the instructors, and the task is decided in such way, that is the students can complete the practice by efforts. There are 4 or 5 instructors and 2 teaching assistants for about 120 students. If any students are in great trouble, instructors and teaching assistants will help them and teach them step by step. In Figure 1, a professor is teaching the students how to design an optical system. In Figure 2, an instructor and 2 teaching assistants are showing how to draw optical system and optical elements.

2. Some students underestimate the difficulties. In the first few days they do not hurry, and in the following days they work from day to night

This is not a good learning habit. So every year we implement the practice project according to the following practice plan in Table 1. The students must complete the work at each time node, or they will lose some of their score. This helps these students complete the practice successfully.

Table 1. Practice plan

Item

Theoretical guidance course

Software development

Optical system design

Drawing

Writing design report

Presentation, defense and upload the report

\section{PRACTICE PLAN}

Period

1 workday

3 workdays

3 workdays (in this period there is a rest of one day )

1 workdays

1 workday

1 workday

As shown in table 1, the whole period of the course is divided into 6 stages. Every stage needs one to three days. The instructors check the achievements of each student group at the end of the 2rd to 5th stage. This plan improves the abilities of time management of the students, and actually they can finish their work on time. Figure 3 shows two interfaces of the software developed by a student group within 3 days. 


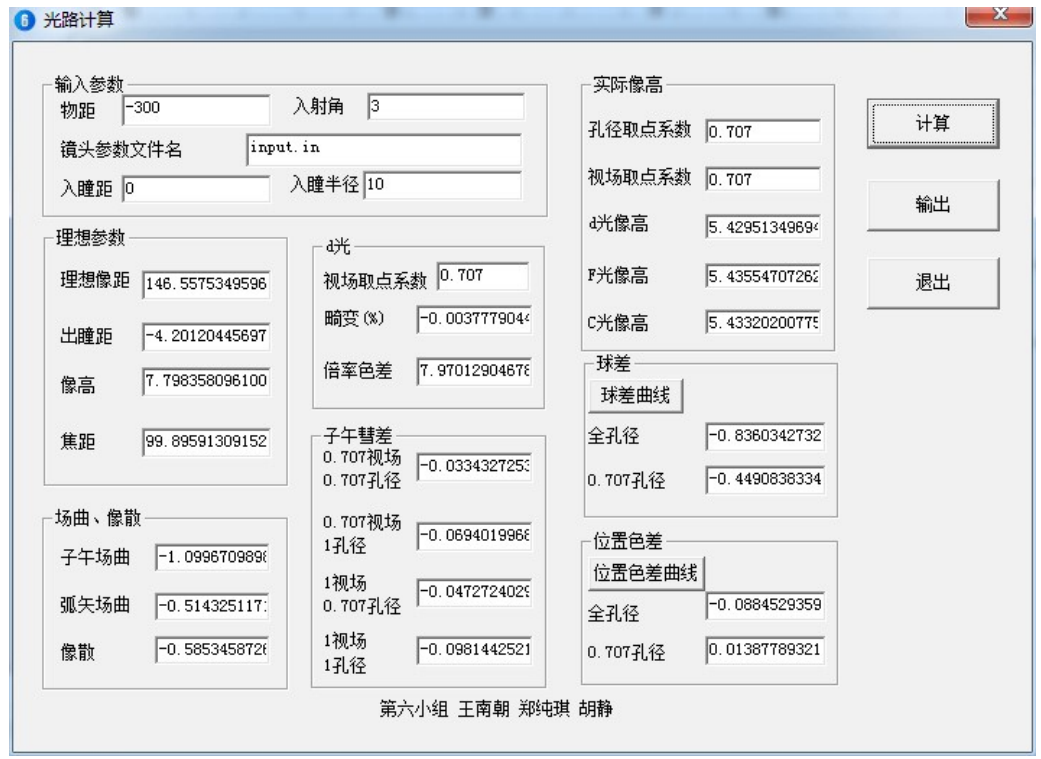

(a)

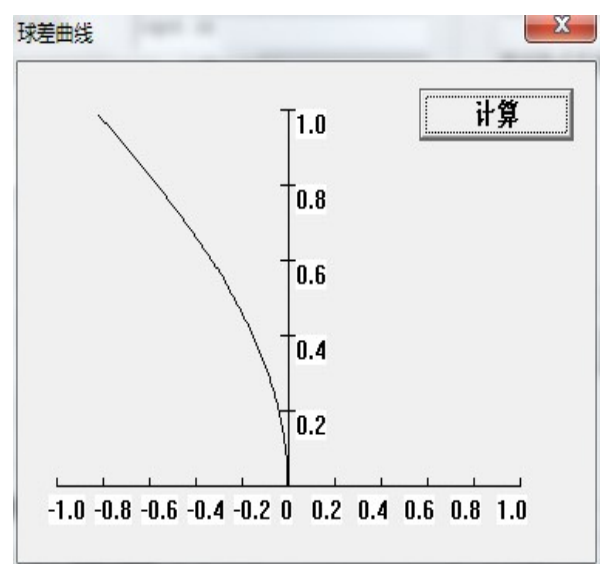

(b)

Figure 3. The interfaces of the software developed by a student group (a) input interface (b) spherical aberration curve

\section{PLURALISTIC EVALUATION SYSTEM}

As the project includes several parts with different requirements, a pluralistic evaluation system is needed. Our evaluation system consists of four parts: software development, optical system design, optical system and element drawing, report presentation and defense. This evaluation system shown in Table 1 has been implemented more than 10 years, and now the percentage of each part has been changed gradually to a reasonable value that is approved by the instructors and students according to our poll each year.

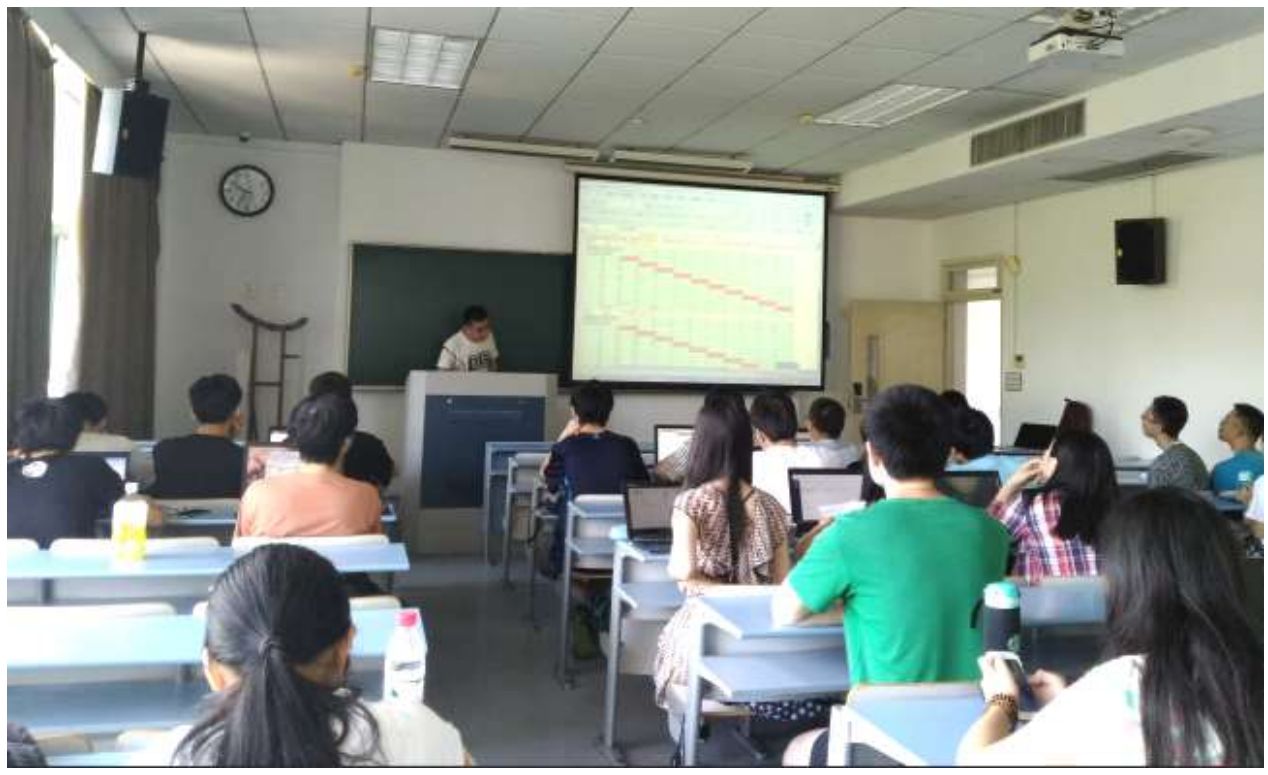

Figure 4. The student groups are scoring each other

In the last day of the practice term, every student group will present the design result in our class. After the defense, the other groups will give the score of this group in each item in Table 2. Finally the highest score and the lowest score are deleted, and the average score is calculated as shown in Figure 4. After the instructors has reviewed the design reports, 
the scores of all the student group will be given. Then the group leader will assign the score to the group members in accordance with their contributions in the project.

This pluralistic evaluation system has implemented for many years, and reviewing of the reports of the whole class and the daily record of the practice term indicates that the evaluation system keeps the students' to get their scores in justice.

Table 2. Pluralistic evaluation system

\begin{tabular}{|lc|}
\hline \multicolumn{2}{|c|}{ PLURALISTIC EVALUATION SYSTEM } \\
Item & Score ratio \\
Software development & $25 \%$ \\
Optical system design & $40 \%$ \\
Drawing & $20 \%$ \\
Report presentation and defense & $15 \%$ \\
\hline
\end{tabular}

\section{CONCLUSION}

This practice course has become a comprehensive training in growing the abilities of our students, includes not only theoretical courses, software development, optical system design, drawings, design reports and defense, but also a very good training in leadership, cooperation spirit, and the ability to complete work in a short period.

This practice is both competitive and cooperative, and is named by the students as "the most memorable short semester". Most of the students are satisfied with their experiences in the short period. The following are some feelings and experiences of the students in their reports:

"I am very like this course. It is a process of independent learning. Teachers help us very kindly and answer my questions timely. We have a large space for personal promotion."

"This design task drives us to think more about how to divide our work and how we can maximize everyone's capabilities when completing projects in the future."

"In this short semester we have learned a lot of professional knowledge. The practice opens the door of optical engineering for us, not only let us see what the future work is like, but also let me recognize the sense of life. These days, though bitter, but the bitter is worth! Hope that in the future I can correct shortcomings and improve myself. "

"This practice gives us a sense of accomplishment and the joy of beyond words. On the other hand, the tasks not only integrate the knowledge I have learned, but also greatly stimulate my enthusiasm for learning. Now I recognize the pleasure of being an engineering student. "

"I believe this course is an unforgettable experience for everyone in our group. We worked together to complete an optical software that we never thought we would complete, and completed a lens design. It is hot this summer, and the sense of accomplishment is also exciting. Thank you very much to my team members, as well as to the teachers and teaching assistants who have been very helpful during the course. I believe this experience will bring great help in our learning and working in future. "

\section{REFERENCES}

[1] Cen Zhaofeng, Li Xiaotong, Liu Xiangdong, Deng Shitao, "Research-oriented teaching in optical design course and its function in education, " Proc. SPIE 6834, 683401(2007).

[2] Voznesenskaya Anna, Romanova Galina, Bakholdin Alexey, Tolstoba Nadezhda, Ezhova Ksenia, "Short educational programs in optical design \& engineering, " Proc. SPIE 9946, 994619(2016).

[3] Fan Changjiang, Ren Zhijun, Ying Chaofu, Peng Baojin, "Practical research on the teaching of Optical Design," Proc. SPIE 10452, 104524F(2017). 